\section{Mulheres e trajetórias na Faculdade de Ciências Médicas da Unicamp: vozes singulares e imagens coletivas}

\section{Women and their careers at Unicamp's Faculty of Medical Sciences: unique voices and collective images}

Maria Inez Montagner

Doutoranda em Saúde Coletiva no Departamento de Medicina Preventiva e Social/Universidade Estadual de Campinas migner@fcm.unicamp.br

Miguel Ângelo Montagner

Professor da Faculdade de Ceilândia/Universidade de Brasília montagner@unb.br

SQN 205, bloco C, apto. 503, Asa Norte 70843-030 - Brasília - DF - Brasil

Recebido para publicação em abril de 2008. Aprovado para publicação em dezembro de 2009.
MONTAGNER, Maria Inez;

MONTAGNER, Miguel Ângelo.

Mulheres e trajetórias na Faculdade de

Ciências Médicas da Unicamp: vozes

singulares e imagens coletivas. História,

Ciências, Saúde - Manguinhos, Rio de Janeiro, vol.17, n.2, abr.-jun. 2010, p.379-397.

Resumo

Apresenta resgate histórico e social da trajetória das professoras da Faculdade de Ciências Médicas da Unicamp e suas escolhas pessoais e profissionais, articuladas às suas estratégias sociais. Abordam-se o papel e a posição dessas mulheres no campo acadêmico, como se conformaram seus habiti e como eles se relacionaram com a questão de gênero. A metodologia, qualitativa, baseia-se nos estudos de gênero e da sociologia da ciência e da saúde, com o uso de entrevistas focadas de Merton e da análise de conteúdo de Bardin. As professoras apontaram as representações sociais sobre família, casamento e filhos, a divisão social do tempo do trabalho e a estrutura patriarcal da ciência como elementos de gênero que influenciaram suas trajetórias.

Palavras-chave: gênero; mulheres; instituições científicas; habitus; medicina.

\section{Abstract}

This article presents a historical and social rediscovery of the trajectories of women professors at Unicamp's Faculty of Medical Sciences and of their personal and professional choices, in conjunction with their social strategies. It explores their roles and positions in the academic world, how they shaped their habitus, and how the latter related to the gender issue. The theoretical reference for the qualitative methodology employed was taken from studies of gender and of the sociology of science and health, including Merton's focused interviews and Bardin's content analysis. The women identified social representations of family, marriage, and children, the social division of work time, and the patriarchal structure of science as gender elements that influenced their careers.

Keywords: gender; women; scientific institutions; habitus; medicine. 
As mulheres não são nem passivas nem submissas. A miséria, a opressão, a dominação, por mais reais que sejam, não bastam para contar a sua história. Elas estão presentes aqui e acolá. Elas são diferentes. Afirmam-se por outras palavras, por outros gestos. ... Elas traçam um caminho que seria preciso reencontrar.

Michelle Perrot, Uma história diferente

$\mathrm{P}$ ara Merton (1970, p.652), a palavra ciência pode significar um conjunto de métodos para obtenção e comprovação do conhecimento, um acervo acumulado por esses métodos, ou um conjunto de valores e costumes culturais que governam as atividades chamadas científicas. Entre essas acepções, interessa-nos a terceira, especificamente os valores e costumes que regem as relações entre gêneros no campo científico. Isso nos insere na tradição de estudos da chamada sociologia da ciência, reflexiva por definição. Ela é a condição de base para qualquer esforço de pesquisa empírica ou teórica, sendo uma necessidade cada vez mais presente nas sociedades modernas. Merton a define como um ramo de estudos voltado a entender "o ambiente social desta classe particular do conhecimento [ciência] que provém da experimentação e observação controladas e voltadas para elas" (p.631).

A presença e importância das mulheres no universo científico têm cada vez mais se tornado um fato incontornável, a despeito da sua invisibilidade nas hagiografias laudatórias dos grandes feitos nesse campo. Segundo Perrot (2005), um dos maiores desafios enfrentados pelos historiadores que estudam as mulheres do século XIX, é o 'apagamento' dos traços públicos e privados na esfera econômica e social.

$\mathrm{Na}$ vertente da sociologia da ciência, o tema foi 'recentemente' descoberto e passou a representar uma vertente vigorosa de estudos. Esforços mais sistemáticos e institucionais têm sido realizados com o objetivo de expor publica e academicamente o problema e sugerir soluções (Tabak, 2002). Pode-se mesmo afirmar que já existe uma tradição de estudos nessa área. Sobre as principais correntes de pensamento sobre a participação das mulheres no campo científico, Citeli (2000, p.47) propõe dividi-las em duas: "de um lado, mulher e ciência reunindo esforços de pesquisa voltados para estudar a participação, a contribuição e o status das mulheres nas carreiras científicas; de outro, gênero e ciência, estudos voltados à análise das implicações de gênero para a, e na, produção das ciências (especialmente as biológicas)". Nosso estudo procurou responder à relação mulheres e ciência dentro da primeira corrente, ainda que algo da segunda vertente - gênero e ciência - venha a ser discutido.

Para compreender os conflitos entre os pesquisadores, as lutas concorrenciais pela legitimidade científica e as estratégias individuais ligadas a uma trajetória de vida, pensamos ser muito mais fértil a utilização do instrumental analítico de Pierre Bourdieu (1983), em especial o conceito de campo, que seria um espaço social determinado por uma lógica relativamente autônoma e apartado simbólica e institucionalmente de outros espaços sociais.

Na nossa pesquisa, é crucial compreender as relações de poder que envolvem os atores sociais, quer sejam homens ou mulheres, para que possamos desconstruir e trazer à luz as 
definições sobre o que é 'ser feminino' para a sociedade. Nesse ponto, julgamos ser significativo o conceito de habitus, também de Bourdieu, que se refere a todas as influências que os indivíduos recebem na sociedade. Tais influências marcam as ações práticas e os padrões de comportamento, sejam eles sociais ou culturais:

Os condicionamentos associados a uma classe particular de condições de existência produzem os habiti, sistemas de disposições duráveis e transferíveis que funcionam como princípios geradores e organizadores das práticas e das representações que podem ser objetivamente adaptados a seus fins sem supor a intenção consciente desses fins e o controle expresso das operações necessárias para atingi-los, objetivamente regrados e regulados sem ser em nada o produto da obediência a regras, e coletivamente orquestrados sem ser o produto da ação organizadora de um maestro (Bourdieu, 1980, p.89; tradução livre).

Neste estudo, assumimos que o habitus, primeiro construído na família e seguidamente na escola e nas instituições, tem papel importantíssimo e está na raiz das questões de gênero, em virtude de sua mediação nas representações do masculino e do feminino.

Segundo Scott (1988), construiu-se na sociedade um lugar social e cultural para o homem e outro para a mulher. $\mathrm{O}$ que se pretende, quando se faz uma análise baseada em gênero, é procurar elementos que descortinem esses lugares onde se delimitaram as atitudes, os comportamentos e os preconceitos concernentes ao sexo. Assumimos a proposta de Schienbinger (2001, p.46), de que "gênero, então, denota entendimentos multidimensionais e mutáveis do que significa ser um homem ou uma mulher no interior de um determinado ambiente social. Ele é historicamente contingente e constantemente renegociado em relação a divisões culturais tais como status, classe e etnia". Segundo Saffioti (1969), gênero não é sinônimo de mulher; ele regula, além da relação homem/mulher, a relação entre as mulheres e entre os homens.

A proposta de Bourdieu era desvelar as formas pelas quais se implantam as disposições, que nada mais são que uma tendência de reagir, de maneira socialmente construída, e muitas vezes pré-reflexivamente, a situações. Para ele, a naturalização das relações estaria presente com mais força nas instituições, como na família, na escola, no mercado de trabalho, enfim, em todos os lugares de reprodução social e transformação das relações. A abordagem construtivista de Bourdieu não nega os espaços políticos e sociais já 'conquistados', considerando que suas análises procuram compreender os mecanismos da dominação e não sugerir sua manutenção, nem mesmo mostrá-la como intransponível, pois quando compreendemos os meios da opressão fica mais fácil transgredi-la e superá-la.

Procuramos, em nossas análises, não enfatizar o êxito dessas profissionais, para não induzir à ideia de incapacidade das outras mulheres que não atingiram uma posição parecida, pois como aponta Saffioti (1969, p.332), "a ideologia do êxito pessoal é amplamente usada nas sociedades de classe para desviar a atenção das pessoas da estrutura social e das severas limitações que ela impõe a determinadas classes sociais".

Os anos 1970, época em que a economia do país teve forte crescimento, foram seguidos por séria crise econômica no decênio seguinte. Nesse período percebe-se uma grande preocupação das ciências sociais com o trabalho desenvolvido pelas mulheres, na tentativa de lhes dar 'visibilidade' (Sarti, 1985). 
Nosso estudo lidou com mulheres de classe média com caracterísiticas específicas: elas tinham ou tiveram menos filhos e recebiam salários melhores, o que lhes garantia arcar com as despesas de escolas e redes de apoio. Bruschini (1988, p.133) enfatiza que "um trabalho mais gratificante e a possibilidade de obter rendimentos satisfatórios atrairiam as mais escolarizadas para o exercício de atividades profissionais fora de casa". Durante certo perído, os estudos sobre a inserção feminina no mercado de trabalho passaram a dar ênfase às características sociais das mulheres, às condições que elas dipõem ao entrar nesse mercado e ao que podem oferecer (Bruschini, 1994a).

O movimento feminista mudou a participação da mulher no cenário público e promoveu seus direitos sociais. Ele não aconteceu de uma hora para outra, pois desde as revoluções do século XVIII as mulheres vêm lutando por direitos e igualdades. Segundo Hobsbawm (1995, p.310), essas lutas não foram inglórias e seus esforços resultaram em reais mudanças no sistema econômico, não só nos países capitalistas como também nos socialistas. Ele considera que essas pequenas conquistas foram primordialmente obtidas por mulheres que pertenciam à classe média e, portanto, tinham problemas referentes à sua posição social: suas motivações para entrar no mercado de trabalho formal dificilmente eram somente econômicas (p.313).

Acreditamos que refletir sobre relações de gênero implica repensar, entre outras coisas, a sua relação com a representação sobre a família e as relações entre os sexos. Considerando que essas mulheres são intelectuais, pareceu-nos relevante, do ponto de vista sociológico, estudar a forma como organizaram suas vidas nas dimensões profissionais, científicas e familiares. Isso é igualmente importante para a compreensão da desigualdade de gênero e do processo de transformação nas relações sociais entre homens e mulheres.

Dessa forma, as diversas narrativas apontaram, a nosso ver, para uma trajetória típica de toda uma geração ou de um grupo específico de mulheres, e de certa forma traçaram alguns eixos representativos comuns, discutidos nos resultados.

\section{Objetivo}

Toda inovação afronta o grupo que desfruta de prestígio, isto é, as estratégias de subversão das vanguardas sempre causam um conflito de poder traduzido em lutas em torno dos objetos científicos (Bourdieu, 1976). Nosso intento foi discernir sinais de lutas concorrenciais e compreender como os problemas de gênero assumiram relevância dentro de uma instituição médica. Analisamos as trajetórias sociais de um grupo de mulheres intelectuais, como forma de desvelar as relações de poder, por meio do delineamento dos habiti das professoras e de suas trajetórias acadêmicas.

Assim, nossa pergunta central foi: qual o habitus das mulheres cientistas da Faculdade de Ciências Médicas (FCM) e como esse habitus interferiu tanto na prática cotidiana da ciência como nas suas vidas pessoais.

\section{Objeto}

Nosso objeto de estudo foi um grupo de professoras plenas da FCM, constituído ao longo de mais de quarenta anos da instituição (1963-2007), num período que coincide 
com as mudanças mais significativas nas relações de gênero, na sociedade brasileira. A constituição desse grupo e sua inserção na academia foi nosso foco de atenção, sobretudo por meio de seus discursos.

Para delinearmos o habitus dessas mulheres, traçamos a sua biografia coletiva a partir da abordagem proposta por Montagner (2007), dado que elas são oriundas de um grupo social mais ou menos homogêneo, portador de um habitus comum e que percorreram uma trajetória coletiva homóloga. Assumimos que toda biografia comporta, na verdade, uma trajetória dentro de um campo social, e que "toda trajetória social deve ser compreendida como uma maneira singular de percorrer o espaço social, onde se exprimem as disposições do habitus" (Bourdieu, 1996, p.292). As relações pessoais e as instituições pelas quais as professoras passaram formaram suas identidades femininas.

\section{Seleção das professoras}

A escolha da pós-graduação deu-se porque esses programas interferem diretamente no modo de recrutamento, na seleção, atração, legitimação científica e formação de grupos. No Brasil, é quase exclusivamente na pós-graduação que se formam os continuadores das linhas de pesquisa, ou os instauradores de novas práticas na ciência. Por meio dela distribuem-se verbas de pesquisa e recursos para a formação de recursos humanos.

Em 2005, a FCM possuía, em seus quadros, 389 professores (Unicamp, 2005). Excluímos desse total os professores não habilitados na pós-graduação, por não atenderem aos requisitos mínimos de cada programa, os professores visitantes e aqueles alocados em mais de um programa de pós-graduação, alcançando o total de 220 professores denominados plenos. Desse total, excluímos 21 professores do programa de pós-graduação em enfermagem, um caso à parte por suas características diferenciadas. O total obtido de 199 professores plenos era composto por 115 homens (58\%) e 84 mulheres (42\%). Do universo das mulheres, selecionamos uma amostra estratificada por programas de pós-graduação para as entrevistas, o que resultou em cerca de um quarto das 84 professoras plenas.

\section{Metodologia}

A metodologia adotada foi qualitativa, baseada na história de vida. Assumimos que o nosso interesse nas percepções de um grupo restrito de professoras da instituição, mas representativo de todo o conjunto das mulheres, reclamava esse tipo de abordagem, ligada às percepções simbólicas e representações do feminino socialmente construídas no tempo.

Utilizamos as informações constantes nos currículos da Plataforma Lattes para realizar nosso trabalho de campo, ou seja, as entrevistas focadas e a análise de conteúdo.

Empregamos como modelo as entrevistas focadas - focused interviews - propostas por Merton, Fiske e Kendall (1956, p.3), que buscam recuperar as trajetórias das mulheres pesquisadas. Esse tipo específico nos pareceu mais apropriado porque, conforme a proposta dos autores, tanto as pessoas entrevistadas estiveram envolvidas em uma situação particular (fizeram suas carreiras na mesma instituição), como a entrevista foi centrada em torno das suas experiências subjetivas decorrentes dessa situação. 
Nas entrevistas, levamos em conta um conjunto de conhecimentos prévios que recolhemos sobre o tema e que traçaram o foco, a direção e o caminho imprimidos durante a entrevista. Por meio da metodologia da história de vida, realizamos uma análise da trajetória pessoal de cada pesquisadora e suas histórias pessoais. Almejamos atingir uma compreensão melhor do universo dessas professoras, adotando como objetivos "a descrição do caso individual, a compreensão das especificidades culturais mais profundas dos grupos e a comparabilidade de diversos casos" (Minayo, 2004, p.122).

Como parte de nossas estratégias, lançamos mão da análise de conteúdo do tipo temático, em consonância com o modelo de entrevistas focadas adotado na pesquisa (Bardin, 1979). Construímos o corpus por meio de agrupamento das entrevistas, de acordo com as características comuns (Minayo, 2004). Como resultado da análise, elencamos algumas categorias, e constatamos que muitas delas já existiam na literatura de gênero, porquanto correspondiam a uma tradição de estudos na área. Nosso papel foi atualizá-las no contexto da instituição estudada. As categorias são: trajetória e biografia; família, casamento e filhos; divisão social do tempo; atividades acadêmicas; ciência.

As categorias foram sintetizadas, analisadas e agrupadas, sempre de forma a contemplar a problemática de gênero em cada momento da trajetória social das mulheres. Cabe ressaltar que, para Bourdieu, a trajetória social reflete o resultado das reelaborações progressivas do habitus: ela afeta, influencia e altera, por meio das escolhas estratégicas realizadas pelo sujeito, a identidade social do indidvíduo.

\section{Resultados}

Como forma de apresentação, trabalhamos com as entrevistas como um conjunto, selecionando falas representativas para compor um quadro de significados articulados e trançados na forma de texto. Nele, procuramos seguir as argumentações e contradições, com suas lógicas e suas relações com as teorias. As falas representam ideias significativas sobre o assunto e não pretendem ser a discussão em si, mas sim exemplos a ilustrar o que o grupo de mulheres como um todo apontou como significativo. As mulheres foram citadas sob nomes fictícios.

\section{Categoria: trajetórias e biografias (histórias de vida e gênero)}

A trajetória e o gênero relacionam-se dialeticamente, pois fazem parte do mesmo universo empírico. Como indivíduos, somos membros de famílias pertencentes a uma determinada classe social e espaço geográfico, recebendo influências de ambos. Essa posição no espaço social reflete-se em nossa formação e nas relações de gênero. Ao analisar as trajetórias das professoras entrevistadas, pudemos perceber que inúmeros fatores contribuíram para a formação de suas identidades e as fizeram acreditar na possibilidade de serem pesquisadoras.

Pudemos constatar que todas as 17 mulheres entrevistadas dizem ter origem social de classe média, entretanto três se classificam como classe média alta e quatro, como classe média baixa. Para se manter durante o curso de graduação, três delas recorreram ao magistério em curso pré-vestibular, deram aulas de violão, fizeram plantões em prontosocorro, ou trabalharam como babá. 
Seus pais tiveram diferentes profissões: bancário, político, dois trabalhadores não especializados, dois professores, mecânico, desenhista, marceneiro, pecuarista, prático de farmácia, três agricultores, engenheiro-agrônomo, representante comercial, comerciante. Entre a ocupação das mães, encontramos: uma enfermeira, uma inspetora de alunos, seis professoras e nove donas de casa. Note-se ainda que nenhum dos pais das entrevistadas era médico ou médica.

A situação econômica das famílias propiciou as condições financeiras necessárias para prosseguirem nos estudos. Formação e estudo eram considerados valores importantes, pois as entrevistadas, excetuando-se duas, enfatizaram que seus pais acreditavam que elas deveriam dedicar-se, primeira e especialmente, às suas formações, não só como forma de prestígio e ascensão social, mas principalmente como um meio de autonomia, liberdade e crescimento individual.

Sobre suas formações, 12 afirmaram ter estudado em escolas públicas e cinco em particulares. Quanto às primeiras, cabe a ressalva: o ensino nessas escolas, à época de sua formação, era de excelente qualidade, segundo os relatos. Contava-se com profissionais de bom nível, e as estruturas e dependências eram de boa qualidade. Entretanto, muitas relataram que ainda estudaram em salas separadas dos meninos e que isso só mudou posteriormente.

Apesar de as trajetórias das mulheres se inserirem na lógica econômica do mundo capitalista, em que a categoria trabalho tem um peso muito grande, a participação das mulheres na produção econômica não as colocou em condições de igualdade sexual (Vaitsman, 1989, p.29). Esses reflexos foram discutidos nas categorias encontradas.

\section{Categorias: família, casamento e filhos; divisão social do tempo}

Um aspecto relevante do nosso estudo foi a análise dos discursos das mulheres no que se refere à conciliação da vida pessoal e profissional, ou seja, como o habitus se projetou na prática cotidiana das cientistas, tanto na academia como em sua vida privada. Percebemos que boa parte das mulheres não se deu conta das discriminações por que passou. Concluímos que isso está de tal forma integrado em suas práticas cotidianas e em seu ethos - em suma, em seu habitus - que o maior desafio foi, tanto para nós como para as professoras, discernir as diferenças de gênero. Muitas vezes as opiniões foram expostas de forma reticente, especialmente quando se referiam às relações de gênero. Como sintetiza Helena: "Eu acho que se você é competente, independentemente de ser homem ou mulher, consegue as coisas. As instituições que apoiam as pesquisas não se preocupam com isso; o que elas se preocupam é com a qualidade do que você faz, com o seu perfil, e eu nunca me senti discriminada".

As relações de poder que se estabelecem entre homens e mulheres que participam de uma sociedade e de um tempo histórico determinados, relações estas incorporadas pelo processo de socialização primária, extravasam, por meio dos habiti, em inúmeras situações. Isso transparece na fala de Beatriz, que valoriza a forma 'masculina' de comando:

Porque, na infância, as mulheres aprenderam que elas têm que ser amiguinhas: "Vamos andar todas juntas, vamos sentar ao lado da mesa; nós somos iguais e nós vamos discutir tudo". É assim que funciona em determinados departamentos cuja maioria é de mulheres: não fazem nada se não for com reuniões, todas iguais. A chefe é eleita, e tem que pedir a 
opinião de todas para tomar qualquer decisão. Esse é um mundo feminino, que já é colocado desde a infância, e não é aceita a posição da mulher que chega e dá uma ordem; isso é complicado. ... Mas elas aceitam a hierarquia quando vem de um homem e não quando vem de uma mulher. Isso é que dificulta, e são questões que não mudaram nesses poucos anos.

A 'inconsciência' das professoras quanto aos constrangimentos em razão do sexo pode ser compreendida ao elucidarmos as concepções sobre gênero que permearam as trajetórias das mulheres, isto é, o que seria para elas o 'feminino'. Embora tenha havido mudanças significativas nas relações de poder, ainda se vive um momento de fortes contradições, resultado de um processo histórico de rupturas.

Em geral, podemos perceber que o modelo do feminino ganhou mais força, como para Sofia: "Eu sou uma pessoa vaidosa e procuro estar sempre arrumada, mas sem exageros; sou feminina nesse ponto... Tem gente que não tem coragem de assumir que é uma mulher vaidosa e se cuidar, mas eu sou". No entanto, a feminização 'excessiva', no local de trabalho, não é bem vista. A ideia é que na universidade deve imperar um vestir sóbrio e uniformizado, com o uso do jaleco ou avental. Isso vem de longa data: já na época do professor Zeferino Vaz, o implementador da Unicamp, era obrigatório o uso de saias, pois o uso de calças na reitoria era entendido como um confronto. Nas palavras de Alice: "O Zeferino não gostava que usassem calça comprida; isso em 1977, 1978. O pessoal gozava porque eu nunca usava saia, só quando ia para a reunião. Todos já sabiam: 'Ah, você tem reunião hoje, não?' - porque eu estava de saia". Logo, esses são valores até mesmo deontológicos: "Quando elas entram aqui [no Hospital, para iniciar o aprendizado clínico], no terceiro ano, é um absurdo o jeito que vêm vestidas. Não pode, isso agride o paciente, e isso a gente tem que ensinar. É um absurdo ter que ensinar que tem de usar avental, elas virem com determinadas roupas. Isso era para já estar embutido na educação, mas não está".

Para trabalhar num ambiente 'masculinizado', a opção de muitas foi assumir uma postura de seriedade e restringir seu comportamento ("fazer-me respeitada"), o que de certa forma implicou incorporar o comportamento masculino ("dar botinadas"), como apontou Patrícia.

As caraterísticas femininas são socialmente construídas e, entre elas, a maternidade parece ser o fulcro em torno do qual se formam muitas das outras representações da feminilidade. A maternidade é um problema quando se pretende seguir uma carreira que requer tempo integral e excelência profissional. Bruschini (1994b, p.69) considera "a presença de filhos o que interfere de forma mais marcante na participação feminina no mercado de trabalho". 'Paternar' e 'maternar' são práticas que variam de uma cultura para outra e são entendidas de diversas maneiras na sociedade. Ambas significam cuidar com afeto, mas nas sociedades capitalistas só as mulheres costumam desenvolver tal habilidade (Saffioti, 2004).

A história das mulheres na universidade nunca foi tranquila quanto ao tema da gravidez e dos filhos, considerando-se as condições de trabalho. Todas declararam que, em algum momento de sua vida de mães, tiveram que optar entre o cuidado com os filhos e suas atividades profissionais. Não só a cobrança sobre a própria participação como mães, mas também como sofriam o olhar do outro, marcado pelo peso social, foi motivo de desistência de determinados projetos. Esse período é emblemático e foi estudado por diferentes autores: a coincidência dos anos de projeção profissional com os anos de fertilidade. 
Exemplos como a forma como se conduziu a negociação sobre uma licença, após o nascimento do filho de Margot, mostram-nos essa situação: "Em relação ao plantão, eu falei para o preceptor de plantão, que era amigo de meu marido: 'Professor, eu queria pegar plantões para Natal e ano-novo em troca do mês do nascimento de meu filho'. Mas ele foi meio machista - aliás, na residência eu senti isso -, porque olhou bem para mim e falou: 'Eu tenho uma solução para você... tem um jeito muito fácil: larga a residência'".

Várias outras declararam dedicar-se ao trabalho depois que seus filhos dormiam, pelo menos por algum tempo durante suas carreiras, sobretudo logo após o nascimento das crianças. Mesmo entre as professoras que eram contratadas pela universidade, a falta de profissionais fazia com que muitas tivessem de abrir mão de alguns direitos para prosseguir com suas atividades de ensino (Helena).

Como apontou Margot, a universidade não apoiava esse grupo social, pois "não tinha creche, nenhuma infraestrutura para a amamentação - não pensaram nisso, imagina! na área da saúde, sendo que no curso isso é muito enfatizado". Isso corresponde ao que observou Schienbinger (2001, p.69): "As instituições científicas - universidades, academias e indústrias - foram estruturadas sobre a suposição de que os cientistas seriam homens com esposas em casa para cuidar deles e de suas famílias". De fato, várias entrevistadas reconheceram ter 'desacelerado' sua trajetória de qualificação profissional quando decidiram ser mães, deixando assim em segundo plano suas profissões e carreiras.

Margot sentiu uma grande pressão do mundo profissional, mas se mostrou contraditória: "Eu tive muitos problemas com as mulheres. Eu entendo, em função da minha história de vida, mas todas ficaram grávidas no mestrado e no doutorado e por conta disso as coisas não andam no tempo que deveriam andar. Não é que eu me incomode com isso, eu entendo".

A culpa pela ausência em casa ou falta de tempo no trabalho foram constantes para Anita, que afirmou: "quando eu estava estudando, me sentia culpada porque deveria estar cuidando das crianças, mas, quando estava com as crianças, me sentia culpada porque achava que deveria estar estudando".

Margot, sabendo da importância da amamentação, especialmente nos primeiros seis meses de vida de uma criança, rememorou com tristeza:

Eu estava no estágio de pronto-socorro, não tinha banco de leite e era um local muito impróprio para que alguém me levasse o nenê para eu amamentar; era impossível. Um dia - estava fazendo um curativo e estava bastante aflita porque o leite estava vazando peguei uma gaze e coloquei como se fosse um tampão. Tive uma mastite violenta, saía pus, tive que tomar [nome do remédio]; foi terrível para mim. ... E quando qualquer pessoa me perguntava se eu tinha amamentado, se eu respondesse que sim eu chorava, se respondesse que não também chorava.

Uma constatação essencial foi a importância das redes de apoio e das instituições responsáveis pela guarda e pelo cuidado da criança. Segundo Helena Hirata (2004), uma tendência na Europa é a contratação do trabalho de empregadas para resolver o problema doméstico, pois "esse 'modelo de delegação' tende a se superpor, senão a substituir, o 'modelo de conciliação' da vida profissional/vida familiar" (p.18). Cinco das professoras entrevistadas disseram que recorreram a suas mães e sogras para cuidar de seus filhos, quando estes eram 
menores; quatro recorreram a babás; duas deixaram com a mãe e a babá revezando os cuidados; uma tinha empregada que fiscalizava os cuidados da babá; três utilizaram escolinhas e creches; uma tinha empregada, mas era o avô e a tia que 'fiscalizavam' o cuidado; e uma recorreu a uma sobrinha, que cuidava das crianças e aproveitava a estada na casa para estudar. Simone teve uma história como essa: "Eu tive uma empregada que foi o sustentáculo da minha vida. Ela já morreu; morava na minha casa. Era ela que organizava tudo, e também tinha uma babá que levava minhas filhas à escola, levava ao parquinho. As minhas filhas acham que fui uma mãe excelente, mas eu não acho".

Segundo Helena Hirata (2002), a crise conjugal, no Brasil, só não se torna maior graças às redes de apoio de empregadas, pais e parentes, que se incumbem de auxiliar as mulheres em suas tarefas de mãe e trabalhadora. Para ela, embora tenha havido um significativo aumento da participação da mulher no mercado de trabalho nos últimos anos, inclusive como fenômeno da reestruturação produtiva, os papéis sociais do homem e da mulher não se alteraram no espaço doméstico, e ainda recai na mulher uma parcela maior de responsabilidade nas atividades e cuidados com as crianças.

Não preencher as expectativas sociais significou, para algumas, romper seus casamentos e, para outras, renegociar a relação. Das mulheres entrevistadas, apenas uma se casou antes de fazer o curso universitário; todas as demais se casaram no decorrer ou no final de seus cursos. Um exemplo típico é a trajetória de Margot: "A gente começou a namorar no meio do primeiro ano e se casou quando eu estava no quinto ano".

Em alguns momentos, quando estavam em início de carreira, foi determinante para algumas entrevistadas estarem casadas com alguém reconhecido e com capital científico. Teresa afirma: "Cheguei [nessa área] - eu brinco - por osmose: a decisão inicial foi do meu marido, a trajetória inicial foi dele, mas pela nossa boa convivência, fui fazendo, sem perceber, uma imersão nessa área".

Das 17 mulheres entrevistadas, 13 tiveram um único marido, uma casou-se pela segunda vez há vinte anos. Nenhuma se casou pela terceira vez. Três mulheres que permanecem até hoje divorciadas contaram que mantêm excelentes relações com seus ex-maridos.

Muitas conciliaram vida afetiva e trabalho, mas Sofia constatou dificuldades: "A mulher que resolve fazer isso - você pode ter certeza - faltou na reunião de escola de filho, deixou de assistir aquela apresentação de balé, deixou de ir naquela festa de dia das mães que você tem que ir. Eu assisti muitos casos assim, e hoje elas falam: 'Meu filho cresceu e eu não vi'. $\mathrm{Eu}$ vi os meus, mas enquanto eu estava vendo os meus filhos crescerem, a pessoa estava subindo. São escolhas, não?".

Sobre a relação entre casamento e carreira, podemos citar a fala de Simone, que ao comparar seu trabalho ao de uma profissional também muito respeitada em sua área, respondeu de forma clara: "Mas pense bem: ela é separada, eu sou separada, a gente sacrificou algumas coisas. Infelizmente, e sobre isso eu falo: infelizmente". Já no caso de Sofia, sua relação com o marido continuou nos 'velhos moldes', ou seja, a cobrança para que desempenhasse suas 'funções femininas' foi constante, e o relato de sua história é exemplar do conteúdo latente em todas as entrevistas: "Ele jamais foi de ficar me cobrando essas coisas. Mas o que acontece? Se eu ficar aqui até as oito horas da noite, quando eu chegar em casa ele vai estar na frente da televisão vendo jornal, esperando eu chegar para saber o que 
vamos fazer. Ele não toma a iniciativa de sair, comprar uma coisa, para quando eu chegar ter uma coisa mais ou menos preparada. Agora você imagina: isso é no nosso caso, a gente se dá bem".

Hirata (2003, p.149) considera o trabalho doméstico executado pela mulher uma relação entre sexos que "se passa na invisibilidade, pois não se pode mostrar o que se está fazendo, como, por exemplo, a mulher passa o aspirador quando o marido não está em casa e as crianças estão na escola. Esta invisibilidade torna-se social, isto é, o trabalho doméstico não é reconhecido como trabalho porque é invisível". A invisibilidade dessas funções colabora para desvalorizá-las e torná-las desprestigiadas. Essa divisão dos trabalhos domésticos também deve ser relacionada com as mudanças que ocorreram no setor terciário, e, segundo Hirata (2004, p.17-18), esses serviços ainda são realizados pelas mulheres, pois "tais serviços são geralmente associados à força de trabalho feminina. Realizados gratuitamente na esfera dita 'privada' e doméstica, são considerados tarefas 'naturalmente' femininas".

A grande maioria das mulheres relatou que recebia 'ajuda' dos companheiros, termo que nos causou grande estranhamento. Uma vez que o homem é tão responsável pela casa quanto a mulher, o verbo apropriado seria partilhar.

Como se mantinham na família os padrões sociais da divisão de trabalho, eles eram estabelecidos no e pelo confronto interpessoal entre os cônjuges, criando uma enorme área de conflito. Frequentemente esse conflito acabava sendo 'naturalizado' ou racionalizado, como descreve Alice: "Mas quando você tem um filho... se você pega um livro eles vêm ao seu lado, e fazem menos com o pai do que com a gente (...) Quando ele estava fazendo a tese, a gente fez um trato: ele fechava a porta do escritório e podia trabalhar. Mas comigo não tinha isso, a cada pouco eles iam lá".

Conforme constatamos, mesmo no caso de mulheres cientistas, a divisão das tarefas domésticas ainda é determinada pelo gênero e a maior parte da rotina doméstica é executada ou fica sob a responsabilidade das mulheres.

\section{Categorias: atividades acadêmicas e ciências}

Houve e há uma diferenciação na trajetória do trabalho das mulheres em relação à dos homens. Muitas deixaram suas carreiras a passo lento por um tempo, ao acompanhar seus maridos na carreira deles ou cuidar da família e dos filhos.

A partir dos anos 1990, com a mundialização, o perfil feminino passou a ser valorizado em um mercado que exige a flexibilidade de tempo e de habilidades. O grupo estudado atende a esse pré-requisito, dado que aprendeu a flexibilizar seus horários e rotinas (o trabalho dentro de um hospital-escola exige, por princípio, uma rotina diferente). O grande problema é que esse trabalho flexibilizado é visto como inato ou pertencente a um dos gêneros.

A chamada feminização da profissão - ocorrida na época em que as professoras aqui estudadas ingressavam na FCM - abriu questões sobre diferenças de gênero ainda parcialmente conhecidas e seguramente pouco estudadas. Conforme estudos quantitativos realizados na França, a escolha das especialidades está profundamente ligada a espaços desvalorizados da arena médica e nos quais se trabalha com alto nível de estresse, como prontos-socorros e emergências em geral, unidades de terapia com alto índice de morte 
(Jaisson, 1995, 2001). Há dados na literatura, como os apontados por Martin, Arnold e Parker (1988), de que as trajetórias profissionais de médicos e médicas diferem claramente: $70 \%$ das residentes, contra 50\% dos residentes, estavam sendo preparadas em áreas relacionadas ao cuidado primário - em ordem descendente, medicina interna, pediatria, psiquiatria, medicina da família, obstetrícia e ginecologia. E somente $5 \%$ escolheram cirurgia.

As professoras que procuraram especialidades não reconhecidas como 'femininas' ou 'para mulheres' declararam que sempre tiveram de fazer mais ou melhor, pois quaisquer deslizes eram tributados à sua condição de mulher: "Nesses dois anos de residência, tomei muito cuidado para não me pegarem com nada errado ... . Eu me policiei muito, e terminada a residência, naquele exame para ficar no hospital como docente, eu passei, e na frente dos mais velhos até" (Beatriz).

Os relatos não explicitaram os motivos da escolha profissional, sobretudo pelo fato de as profissões estarem determinadas fortemente por influências socioestruturais. Muitas vezes as escolhas são naturalizadas, quando no fundo foram de cunho extremamente social. Poucas conseguiram contrariar a lógica de não poderem, por condições de gênero ou mesmo biológicas, realizar determinadas atividades, como nos contou Beatriz: "É, das áreas cirúrgicas, eu preferi... porque eu achei mais bonito, mais agradável de trabalhar, e eu poderia operar sentada. As cirurgias não são tão longas. Achei que era muito mais adequado para mim, que sou muito baixinha; achei que eu me sentiria melhor. Mas eu queria operar".

Essas competências socialmente construídas e sua influência nas trajetórias das professoras foram significativas. Em nossa sociedade, é muito comum concebermos, para a mulher, o papel de cuidadora, de alguém que 'naturalmente' se encarrega dos cuidados das crianças, dos idosos e dos outros. Tal construção social conforma seus imperativos morais, o que impele a mulher a se encarregar de tarefas que, para os homens, são vistas de forma negativa ou de responsabilidade de outrem (Saffioti, 1969).

O termo care refere-se a um conceito novo, em que se aponta a dimensão moderna dessa utilização de mão de obra, sobretudo a feminina. Um ponto essencial na alteração da correlação de forças entre homens e mulheres seria o reconhecimento de que as qualidades 'femininas' deveriam ser reconhecidas e remuneradas de acordo com sua importância (Hirata, 2004, p.18). Hirata (2004) aponta que houve, com a reestruturação produtiva moderna, uma 'globalização dos cuidados', com uma extensão mercantil do trabalho doméstico e o uso de mulheres pobres no trabalho doméstico das casas das classes mais altas, principalmente. Isso permitiu que mulheres com recursos delegassem às mulheres mais pobres os cuidados do lar, polarizando o trabalho feminino entre aquele em casa e outro no mercado, com o segundo também detentor de 'características femininas'.

Na FCM o care é valorizado no universo de tratamento dos doentes, sendo traduzido pelo termo 'cuidado'. No ambiente acadêmico, as mulheres têm fama de serem professoras e orientadoras mais dedicadas, e essa capacidade de care é um valor para elas, apesar de não ser reconhecida como produtiva e valiosa no mercado de trabalho. Elise faz coro com outras mulheres que acreditam ser relevante, para o bom desempenho profissional, o cuidado nas relações pessoais: "Você está tocando numa coisa que é uma característica minha. Sempre tive muita facilidade para lidar com as funcionárias, tenho uma identificação fortíssima 
com a enfermagem, não sei se é porque aprecio e entendo que o profissional que faz enfermagem tem alma de cuidador e, no fundo, gosto dessa coisa do cuidador".

As professoras apontaram como característica das mulheres uma sensibilidade diferente, o que as torna mais observadoras e organizadas. Um exemplo, na fala de Sofia: "Eu acho que, de maneira geral, a mulher tem uma sensibilidade diferente. Ela pode prestar atenção em algumas coisas, dentro de um departamento, que o homem não vê, É por sermos mais detalhistas, observadoras, sensíveis; são características nossas, graças a Deus, e isso faz a diferença".

O ponto a ser discutido aqui não é comprovar se existe uma ciência essencialmente feminina, masculina ou neutra. Da mesma forma como as práticas sociais estão ligadas às diferenças de gênero, podemos imaginar que a própria ciência é também atravessada pela questão relativa aos universos do feminino e do masculino. Nossa intenção é a mesma procura inicial de Fox Keler (2006, p.16): "minha meta não era tornar a ciência mais subjetiva ou mais 'feminina', mas ao contrário fazê-la mais verdadeiramente objetiva, e necessariamente 'independente do gênero'. Numa palavra, procurava uma ciência melhor. Uma ciência melhor, argumentava, seria inevitavelmente uma ciência mais abrangente, mais acessível às mulheres."

Muitos estudos apontam certa generalidade na visão da ciência como uma prática masculina. Para Fox (1989), estudos recentes têm mostrado uma recorrência, na ciência moderna, de um padrão cultural masculino no ethos científico. Assim, padrões éticos da ciência como razão, objetividade, impessoalidade, autonomia, poder, controle e dominação da natureza são aqueles historicamente associados à masculinidade.

No Brasil, as mulheres estão inseridas há poucas décadas no espaço médico, acompanhando uma tendência verificada em quase todos os países, especialmente a partir dos anos 1970 (Machado, 1997). Nesse processo, as ideias 'fora de lugar' continuavam a grassar na arena médica. Podemos confirmar essa posição na fala de Beatriz: "Na hora que fui saber o resultado do exame da residência, a secretária estava batendo à máquina para publicá-lo. Aí veio um professor adjunto, entrou na sala da secretária perguntando: 'Quem foi o primeiro lugar?'. E eu ouvindo tudo porque estava esperando ela me trazer o papel. Um outro, lá dentro, respondeu: 'Infelizmente foi a moça'. Eu tive um ponto a mais que o segundo colocado, foi muito acima e eles não tiveram condições de manipular a nota, nem nada".

Segundo a maioria das entrevistadas, não existem diferenças entre os sexos quando o assunto é ciência. Mas nas entrelinhas, da mesma forma como na questão das relações de poder, as desigualdades afloraram. Como exemplifica a fala de Teresa: "A ciência independe do sexo, a gente tem profissionais brilhantes tanto do sexo feminino como do masculino. Se eu tivesse casado com outra pessoa, eu nem teria vindo para essa área. Então é um conjunto, vejo tudo muito misturado, não consigo tirar as coisas. Isso não depende do sexo, depende muito mais dessas condições, das oportunidades que são oferecidas". Já Sofia chega a ressaltar que a competição entre as mulheres é pior do que entre os homens: "O problema maior dentro da universidade não é o homem, é a outra mulher que está do teu lado. Por que a mulher, quando resolve ser competitiva, sai de baixo: a mesma garra que ela tem para as outras coisas na vida, começa a ter aqui e passa feito um trator por 
cima de você". Helena, por sua vez, percebe diferenças claras: "O talento dela está no cuidar, no construir mesmo. Nesse sentido, se a ciência é feita por homem ou mulher, há uma cultura muito forte, uma política, uma história de construção científica masculina. A história da geração de conhecimento novo é noventa por cento masculina; a ciência é construída em cima de uma produção masculina".

As caracterísiticas e a presença femininas podem gerar impedimentos 'invisíveis' na academia, traduzidos na idéia do 'efeito do teto de vidro' (plafond de verre). O termo foi cunhado por Henri Etzkowitz e colaboradores, definido por Léa Velho e Elena León (1998, p.331) como "significando que mesmo as mulheres bastante qualificadas são bloqueadas na sua ascensão profissional por práticas discriminatórias, conflitos família-trabalho que as impedem de produzir tanto quanto os homens, e por traços de comportamento adquiridos durante o processo de socialização, que seriam 'desfavoráveis' ao sucesso profissional, tais como falta de agressividade, de ambição, etc.".

Do ponto de vista objetivo, as diferenças ainda se mantêm. O posto máximo da carreira de professor é o de professor titular. Do total de 184 professores plenos da FCM, 24 professores são titulares, dos quais oito são mulheres (Gráfico 1)

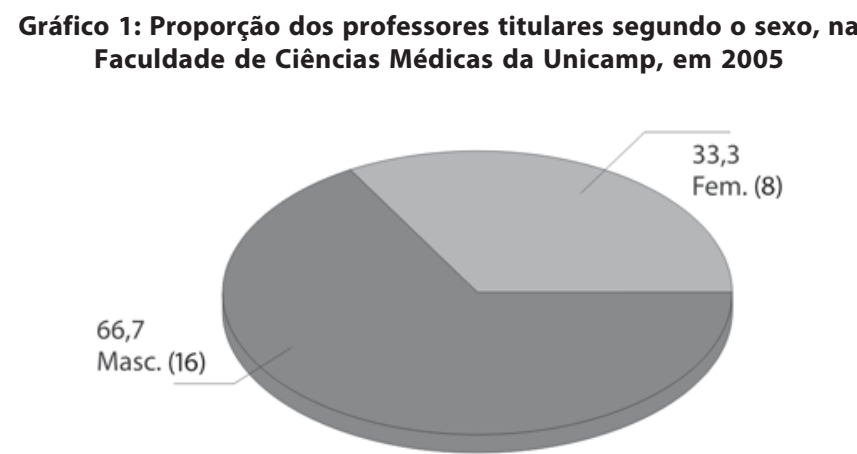

Fonte: (Unicamp, 2005)

Construímos um índice per capita, no qual o número de professores é dividido proporcionalmente à distribuição por sexo dos professores plenos (Montagner et al, 2009). Se utilizamos somente os números brutos, constata-se a ocorrência de muito mais homens do que mulheres entre os professores titulares; com o índice por pessoa, percebe-se que a diferença ainda é significativa, mas é menor do que na proporção bruta (Gráfico 2).

Outro indicador é a proporção bruta de professores livres-docentes, representado no Gráfico 3.

Portanto, permanece uma diferença relevante que merece ser investigada por meio de outros parâmetros. ${ }^{1}$ Haveria um desinteresse das mulheres por essa titulação, haveria um teto de vidro, uma autoexclusão, ou mecanismos reais de alijamento das mulheres?

Sob o aspecto quantitativo, é crescente o número de mulheres nas atividades científicas com maior qualificação profissional. Em áreas ligadas à saúde aumenta o número de pesquisadoras com titulação máxima, embora historicamente os homens ainda predo- 
minem em setores como engenharia e pesquisa tecnológica aplicada (Melo, Lastres, Marques, 2004). Talvez isso seja reflexo da inserção tardia das mulheres no sistema, mas esse também é um ponto de reflexão para outras investigações.

Gráfico 2: Índice per capita de professores titulares segundo o sexo, na Faculdade de Ciências Médicas da Unicamp, em 2005

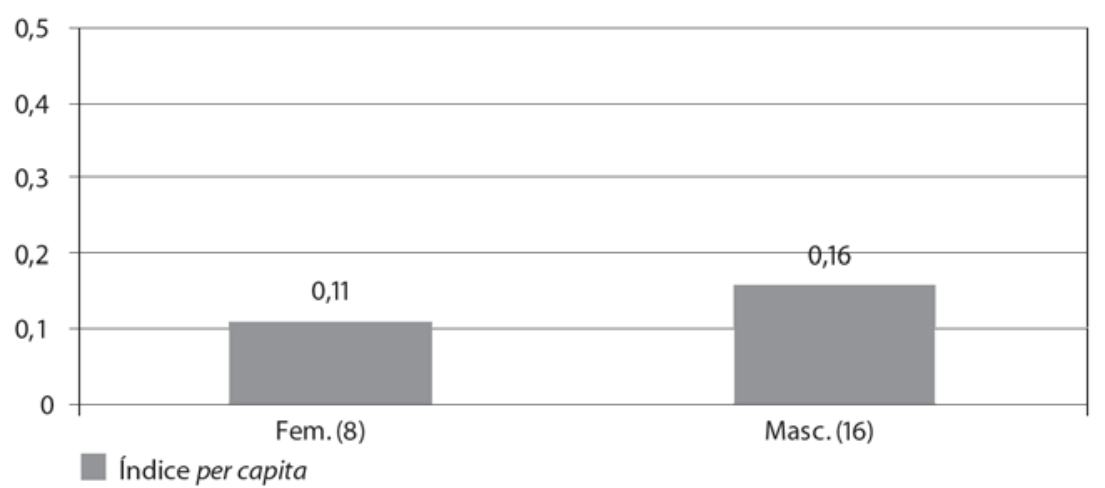

Gráfico 3: Percentual de professores livre-docentes por sexo, na Faculdade de Ciências Médicas da Unicamp, em 2005

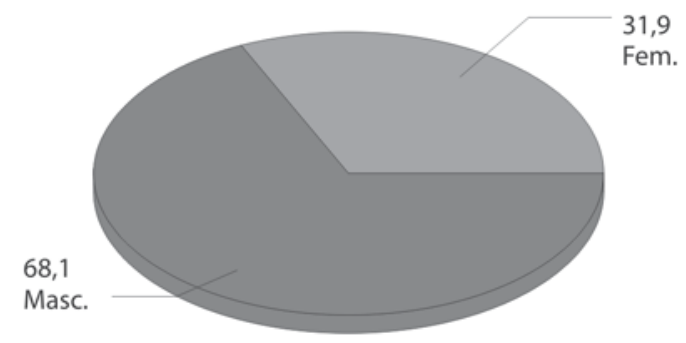

\section{Considerações finais}

Todas as mulheres entrevistadas pertenciam à classe média e seus pais não eram médicos. Para as professoras, o fato de pertencerem à classe média lhes proporcionou a possibilidade de estudar e de viver em ambientes familiares bem menos preconceituosos com relação a suas escolhas profissionais. Essas mulheres, tendo sofrido influência do habitus e das disposições a ele inerentes, assumiram novos papéis que não eram comuns na época de sua formação. Assim, podem ser tidas como precursoras em suas áreas de atuação. De certa forma as mulheres, na academia, representam um movimento de vanguarda desde o início do século XIX.

O nosso objetivo inicial era compreender a ciência e o mundo acadêmico do ponto de vista das mulheres. Em boa parte ele foi alcançado, mas, quanto ao discurso coletivo, percebemos que havia temas prévios, latentes, intocados, que irromperam com força e relevância durante as entrevistas focadas, sobretudo aqueles relacionados às relações familiares, 
ao trabalho doméstico e ao cuidado dos filhos. Quando a análise girou em torno da conciliação entre a vida profissional e a familiar, pareceu-nos a dimensão de maiores conflitos de ordem pessoal, que se refletiam, inclusive, na sua vida acadêmica. Nesse ponto, o tema da família foi extremamente recorrente, o que denota um forte e latente conteúdo conflitual, onipresente em suas biografias. Em geral, as questões de gênero foram vividas de forma individual e resolvidas dessa maneira.

Afirmou-se a igualdade, mas as mulheres ressaltaram que, em virtude dos filhos, investiram menos em suas rotinas profissionais. Quando aprofundamos o tema, percebemos grande quantidade de 'exclusões' e 'autoexclusões'.

As mudanças de comportamento expressas no discurso das mulheres soaram muitas vezes como um objetivo a ser alcançado, mas ainda distante da prática cotidiana das relações conjugais. A maternidade ainda é um assunto de mulher: ela não deve ser analisada somente como uma barreira real e concreta sob o ponto de vista acadêmico e segundo os padrões de pesquisa atuais, mas também como um grande dilema pessoal, afetivo, social e psicológico, pelo qual as mulheres passaram e passam, com todo o grau de sofrimento e culpa a ele associado, agravado pelos resultados das escolhas feitas com os quais elas têm que conviver.

Para avaliar a quantidade de tempo trabalhado por essas mulheres, dividimos o dia em três fases: presencial, familiar e complementar. $\mathrm{O}$ trabalho presencial seria o trabalho remunerado, cujas horas são cumpridas de acordo com o regime de trabalho. No trabalho familiar, resolvem-se as tarefas relacionadas ao lar, aos cuidados e à manutenção da limpeza e alimentação. Mesmo com o auxílio de empregadas ou parentes, esse seria o momento de avaliar a prestação de serviços ou, ainda, dedicar-se ao cuidado com higiene e atividades escolares e extraescolares dos filhos. O trabalho complementar seria uma retomada dos trabalhos pertinentes à sua atividade remunerada que não foram realizados no período da jornada regular. Concluimos que as atividades de lazer e cuidados pessoais são diretamente proporcionais à diminuição do trabalho complementar e, sobretudo, do trabalho familiar. Todas referiram a completa ausência de tempo para o autocuidado e o lazer, ao menos durante os momentos mais críticos da carreira. Poder-se-ia argumentar que o problema talvez seja a profissão escolhida. O modelo de carreira acadêmica faz com que os professores estejam sujeitos a grande quantidade de trabalho e é inadequado tanto para os homens como para as mulheres. Mas o fato é que às mulheres ainda é tributado o trabalho familiar.

Braverman (1981) demonstrou que a degradação do trabalho, no capitalismo moderno, acaba por atrair primeiramente as mulheres para funções mal remuneradas ou desprestigiadas, principalmente no setor terciário da economia. De certa forma, isso persiste no caso da medicina, uma vez que a feminização atual é acompanhada de certo desprestígio e uma diminuição da remuneração profissional. Perrot (1992) relata que o discurso do final do século XVIII enfatizava a ideia de que a feminização da monarquia era a marca de sua decadência.

Acreditamos que a ciência depende das relações de poder que atravessam as relações entre os homens e as mulheres que a produzem. O gênero foi um tema implícito, e alguns discursos nos causaram incômodo. Quando indagamos sobre o exercício do poder na instituição, percebemos que ele é mais 'natural' quando exercido pelos homens. Nos cargos 
de comando, as mulheres ainda não estão presentes com constância, e a hierarquia é mais bem aceita quando um homem exerce o poder.

As mulheres apontam que possuem características diferenciadas que as habilitam para tarefas específicas, no espaço científico. Algumas características sociais como o care são vistas como tipicamente femininas, mas acreditamos que deveriam fazer parte do arsenal de um bom profissional.

Por fim, constatamos uma característica comum e frequente nos discursos analisados, que apontam, nas trajetórias dessas mulheres, para um componente de ousadia e persistência que chamamos de 'síndrome de Ester'. Ester, personagem bíblico, tornou-se rainha ao casar-se com o rei da Pérsia, cujo primeiro ministro elaborou um plano para exterminar os judeus do reino. Ela teve que escolher entre permanecer incógnita e defender a própria vida, ou assumir sua origem judia e defender seu povo. Acreditou em seus ideais e na sua crença, decidiu-se por eles e conseguiu o que queria. Essa síndrome representa a possibilidade de escolha e a predileção pelo caminho novo, em que se investe na inovação, no desafio e no diferente, de forma consciente e com a sensação de absoluta certeza e necessidade, mesmo que a opção traga sérias consequências. Representa a antítese das dificuldades imaginárias ou reais que impedem as mulheres de atingir lugares não 'propícios' ou feitos sob medida para o perfil masculino, como no caso do efeito do teto de vidro.

As professoras percorreram as trajetórias marcadas em seu destino feminino e mantiveram sua identidade feminina. Não foram "mulher na aparência, homem pelo espírito", como Elizabeth Badinter (2003, p.87) relata a forma como Voltaire descrevia Madame du Châtelet, uma feminista avant la lettre. Esse processo foi e é dialético, pois percebemos que alguns discursos foram contraditórios: se com uma das mãos propõem mudanças e valorizam a feminilidade, com a outra reproduzem e incorporam o modelo patriarcal de ciência, sem questionar o espaço social a sua volta. Mas assim se faz a história. Podemos perceber significativas mudanças pelo questionamento das relações de gênero e ciência, como apontou Lopes (2006).

Concluímos com as palavras de Schienbinger (2001, p.31): “As diferenças historicamente elaboradas entre mulheres e homens, então, não podem servir como uma base epistemológica para novas teorias e práticas nas ciências".

\section{NOTA}

${ }^{1}$ Para uma análise global da instituição e dos dados quantitativos dos professores, ver Montagner, Montagner, Hoehne, 2009.

\section{REFERÊNCIAS}

BADINTER, Elizabeth.

Émilie, Émilie: a ambição feminina no século XVIII. São Paulo: Paz e Terra. 2003.

BARDIN, Laurence.

A análise de conteúdo. Lisboa: Edições 70. 1979.

BOURDIEU, Pierre.

As regras da arte: gênese e estrutura do campo literário. São Paulo: Companhia das Letras. 1996.

BOURDIEU, Pierre.

Questões de sociologia. Rio de Janeiro: Marco Zero. 1983.

BOURDIEU, Pierre.

Le sens pratique. Paris: Minuit. 1980. 
BOURDIEU, Pierre.

Le champ scientifique. Actes de la Recherche en Sciences Sociales, Paris, v.2, n.2-3, p.88-104. 1976.

BRAVERMAN, Harry.

Trabalho e capital monopolista. Rio de Janeiro: Zahar. 1981.

BRUSCHINI, Maria Cristina Aranha.

Mulher e mundo do trabalho: ponto de vista sociológico. In: Brandão, M.L.R.; Bingemer, M.C.L. (Org.). Mulher e relações de gênero. Rio de Janeiro: Loyola. p.115-130. 1994a.

BRUSCHINI, Maria Cristina Aranha. $\mathrm{O}$ trabalho da mulher no Brasil: tendências recentes. In: Saffioti, Heleieth; Munhoz-Vargas, Mônica (Org.). Mulher brasileira é assim. Rio de Janeiro: Rosa dos Tempos. p.63-94. 1994b.

BRUSCHINI, Maria Cristina Aranha. Mulher e trabalho: uma avaliação da década da mulher (1975-1985). In: Carvalho, Nanci Valadares de (Org.). A condição feminina. São Paulo: Vértice. p.124-142. 1988.

CITELI, Maria Teresa.

Mulheres nas ciências: mapeando campos de estudo. Cadernos Pagu, Campinas, n.15, p.39-75. 2000.

FOX, Renée C.

The sociology of medicine: a participant observer's view. New Jersey: Prentice Hall. 1989.

HIRATA, Helena Sumiko.

O universo do trabalho e da cidadania das mulheres: um olhar do feminismo e do sindicalismo. In: Costa, Ana Alice et al. (Org.). Reconfiguração das relações de gênero no trabalho. São Paulo: CUT Brasil. p.13-20. 2004.

HIRATA, Helena Sumiko.

Tecnologia, formação profissional e relações de gênero no trabalho. Revista Educação e Tecnologia, Belo Horizonte, n.6, p.144-156. 2003.

HIRATA, Helena Sumiko.

Nova divisão sexual do trabalho?: um olhar voltado para a empresa e a sociedade. São Paulo: Boitempo. 2002.

HOBSBAWM, Eric J.

Era dos extremos: o breve século XX, 1914-1991. São Paulo: Companhia das Letras. 1995.

JAISSON, Marie.

El aprendizaje social y la condición humana. Empiria, Madrid, n.4, p.11-41. 2001.

JAISSON, Marie.

Les lieux de l'art: études sur la structure sociale du milieu médical dans une ville universitaire de province. Thèse (Doctorat) - L'Ecole des Hautes Etudes en Sciences Sociales Paris, 1995.

KELER, Fox.

Qual foi o impacto do feminismo na ciência? Cadernos Pagu, Campinas, n.27, p.13-34. 2006.

LOPES, Maria Margaret.

Sobre convenções em torno de argumentos de autoridade. Cadernos Pagu, Campinas, n.27, p.35-61. 2006.

MACHADO, Maria Helena.

Os médicos no Brasil: um retrato da realidade. Rio de Janeiro: Ed. Fiocruz. 1997.

MARTIN, Steven; ARNOLD, Robert; PARKER, Ruth.

Gender and medical socialization. Journal of Health and Social Behavior, Washington D.C., v.29, p.333-343. 1988.

MELO, Hildete Pereira de; LASTRES, Helena Maria Martins; MARQUES, Teresa Cristina de Novaes.

Gênero no Sistema de Ciência, Tecnologia e Inovação no Brasil. Gênero, Niterói, v.4, n.2, pp.73-94, 2004.

MERTON, Robert King.

Sociologia: teoria e estrutura. São Paulo: Mestre Jou. 1970.

MERTON, Robert King; FISKE, Marjorie;

KENDALL, Patricia L.

The focused interview: a manual of problems and procedures. Illinois: The Free Press. 1956.

MINAYO, Maria Cecília de Souza.

O desafio do conhecimento: pesquisa qualitativa em saúde. São Paulo: Hucitec. 2004.

MONTAGNER, Miguel Ângelo.

Trajetórias e biografias: notas para uma análise bourdieusiana. Sociologias, Porto Alegre, ano 9, n. 17, p.240-264. 2007.

MONTAGNER, Miguel Ângelo; MONTAGNER, Maria Inez; HOEHNE, Eduardo Luiz. A consagração científica em números: análise do perfil de uma vanguarda pelos currículos Lattes. Interface - Comunicação, Saúde, Educação, Botucatu, v.13, n.30, p.181-195. 2009.

PERROT, Michelle.

As mulheres ou Os silêncios da história. Bauru: EdUsc. 2005.

PERROT, Michelle.

Os excluídos da história: operários, mulheres e prisioneiros. Rio de Janeiro: Paz e Terra. 1992.

SAFFIOTI, Heleieth Iara Bongiovani.

Gênero e patriarcado: violência contra mulheres. In: Venturi, Gustavo et al. (Org.). A mulher brasileira nos espaços público e privado. São Paulo: Fundação Perseu Abramo. p.79-80. 2004. 
SAFFIOTI, Heleieth Iara Bongiovani.

A mulher na sociedade de classes: mito e realidade. São Paulo: Quatro Artes. 1969.

SARTI, Cynthia.

Trabalho feminino: de olho na literatura.

Literatura Econômica, Rio de Janeiro, v.7, n.1, p.93-116. 1985.

SCHIENBINGER, Londa.

O feminismo mudou a ciência? Bauru: EdUsc. 2001.

SCOTT, Joan Wallach.

Genre: une catégorie utile d'analyse historique. Les Cahiers du Grif, Bruxelles, Printemps, p.125-153. 1988.

TABAK, Fanny.

O Laboratório de Pandora: estudos sobre a ciência no feminino. Rio de Janeiro:

Garamond. 2002.

\section{UNICAMP.}

Universidade Estadual de Campinas. Catálogo dos cursos de pós-graduação 2005 stricto sensu: Faculdade de Ciências Médicas. Campinas: Unicamp. 2005.

VAITSMAN, Jeni.

Biologia e história ou Por que a igualdade é possível. In: Labra, Maria Eliana (Org.). Mulher, saúde e sociedade no Brasil. Rio de Janeiro: Vozes. p.25-38. 1989.

VELHO, Léa; LEÓN, Elena.

A construção social da produção científica por mulheres. Cadernos Pagu, Campinas, n.10, p.309-344. 1998. 